\title{
Breast cancer hypoxia in relation to prognosis and benefit from radiotherapy after breast-conserving surgery in a large, randomised trial with long-term follow-up
}

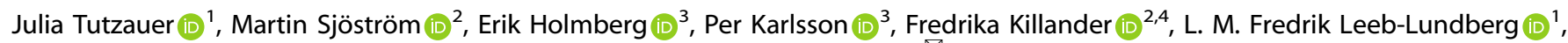
Per Malmström ${ }^{2,4}$, Emma Niméus $\mathbb{D}^{2,5,6}$, Mårten Fernö ${ }^{2}$ and Annika Jögi (iD)

(c) The Author(s) 2021

BACKGROUND: Breast-conserving surgery followed by radiotherapy is part of standard treatment for early-stage breast cancer. Hypoxia is common in cancer and may affect the benefit of radiotherapy. Cells adapt to hypoxic stress largely via the transcriptional activity of hypoxia-inducible factor (HIF)-1a. Here, we aim to determine whether tumour HIF-1a-positivity and hypoxic geneexpression signatures associated with the benefit of radiotherapy, and outcome.

METHODS: Tumour HIF-1a-status and expression of hypoxic gene signatures were retrospectively analysed in a clinical trial where 1178 women with primary T1-2N0M0 breast cancer were randomised to receive postoperative radiotherapy or not and followed 15 years for recurrence and 20 years for breast cancer death.

RESULTS: The benefit from radiotherapy was similar in patients with HIF-1a-positive and -negative primary tumours. Both ipsilateral and any breast cancer recurrence were more frequent in women with HIF-1a-positive primary tumours (hazard ratio, HR $0-5$ yrs 1.9 [1.3-2.9], $p=0.003$ and $\mathrm{HR}_{0-5}$ yrs $=2.0$ [1.5-2.8], $\left.p<0.0001\right)$. Tumour HIF-1a-positivity is also associated with increased breast cancer death $\left(\mathrm{HR}_{0-10}\right.$ years 1.9 [1.2-2.9], $\left.p=0.004\right)$. Ten of the 11 investigated hypoxic gene signatures correlated positively to HIF-1apositivity, and 5 to increased rate/risk of recurrence.

CONCLUSIONS: The benefit of postoperative radiotherapy persisted in patients with hypoxic primary tumours. Patients with hypoxic primary breast tumours had an increased risk of recurrence and breast cancer death.

British Journal of Cancer (2022) 126:1145-1156; https://doi.org/10.1038/s41416-021-01630-4

\section{BACKGROUND}

Breast cancer is the most common malignancy affecting women. Today, breast-conserving surgery followed by radiotherapy (RT) to the affected breast is part of the standard treatment for earlystage breast cancer. Systemic adjuvant therapy is selected based on patient and tumour characteristics and aims to target micrometastatic disease. About $80 \%$ of primary breast tumours express oestrogen receptor (ER) and are eligible for endocrine treatment [1].

RT after breast-conserving surgery considerably decreases the risk for ipsilateral breast tumour recurrence (IBTR), and to a minor extent also distant recurrence, and breast cancer death (BCD) $[2,3]$. However, RT also confers side-effects [4-6], underscoring the importance of identifying potential patient-groups that do or do not benefit from RT. A number of factors that influence the therapeutic effect of RT have been identified in experimental systems, as well as in clinical materials [7]. The availability or shortage of oxygen was early identified as a major influencer of the outcome of RT $[8,9]$.

Oxygen levels are lower than those required to maintain normal metabolism and function in tissue, i.e., hypoxia, frequently occur in tumours, including breast cancer. Hypoxic adaptation at the cellular level is primarily controlled by the hypoxia-inducible transcription factors, HIF-1a and HIF-2a. Both are mainly regulated at the protein level and in response to hypoxia, the HIF alphasubunits accumulate and become activated [10-13]. Tumour hypoxia contributes to tumour progression and therapy resistance, including RT-resistance [14], in direct as well as indirect ways [9]. Oxygen is required to make radiation-induced DNAdamage permanent, i.e. the oxygen enhancement effect. The hypoxic response, conveyed by HIF-induced gene expression, leads to altered metabolism, increased expression of growth factors, proliferation, and expression of cytokines [15]. In breast cancer, HIF-1a protein is a marker of poor prognosis and disease

\footnotetext{
${ }^{1}$ Department of Experimental Medical Science, Lund University, Lund, Sweden. ${ }^{2}$ Division of Oncology, Department of Clinical Sciences Lund, Lund University, Lund, Sweden.

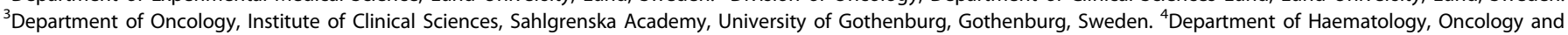
Radiation Physics, Skåne University Hospital, Lund, Sweden. ${ }^{5}$ Division of Surgery, Department of Clinical Sciences Lund, Lund University, Lund, Sweden. ${ }^{6}$ Department of Surgery Malmö, Skåne University Hospital, Malmö, Sweden. ${ }^{7}$ Translational Cancer Research, Department of Laboratory Medicine, Lund University Cancer Center at Medicon Village, Lund University, Lund, Sweden. ${ }^{8}$ Skåne University Hospital, Malmö, Sweden. ${ }^{\bowtie}$ email: Annika.jogi@med.lu.se
}

Received: 4 July 2021 Revised: 17 October 2021 Accepted: 3 November 2021

Published online: 9 February 2022 


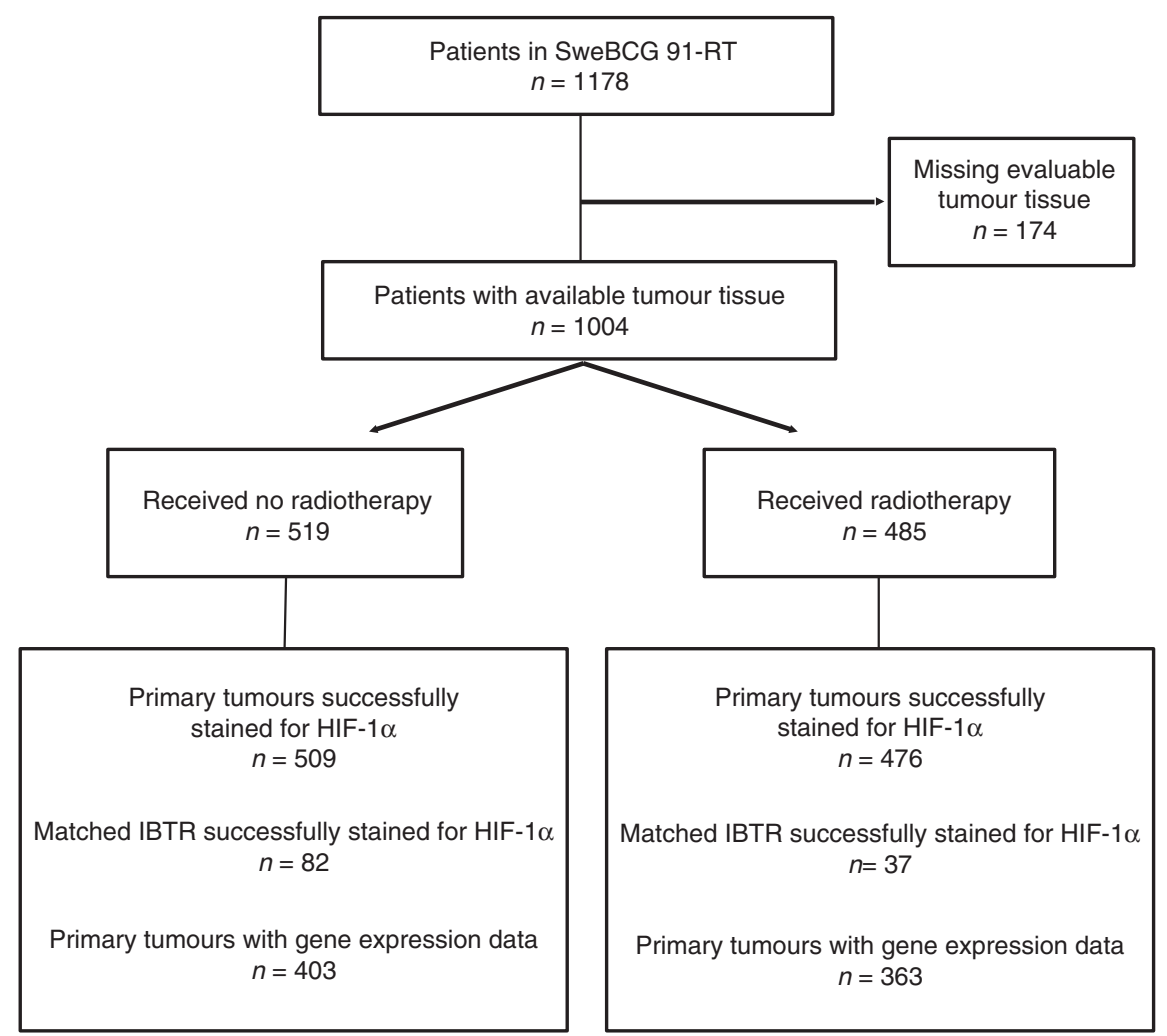

Fig. 1 Study design. Diagram of inclusion and exclusion to the study according to Remark criteria.

progression [16-18]. Upon reoxygenation the half-life of HIF-1a is in the minute range, creating a need for surrogate markers of hypoxia, such as more robust proteins induced by hypoxia, e.g. CAIX or hypoxic gene-expression signatures [19-21].

Here, we primarily aimed to test whether the hypoxia-marker HIF-1a affects the patient benefit of RT in a large population-based cohort with long follow-up of patients randomised to receive postsurgery RT or not after breast-conserving surgery. A second aim was to investigate whether tumour hypoxia and HIF-1a accumulation are associated with IBTR. Finally, we aimed to study whether hypoxic gene-expression signatures could complement or even replace HIF-1a protein detection as a prognostic or predictive marker.

\section{METHODS \\ Patients and study design}

Patients were from the Swedish breast cancer group trial, SweBCG91-RT, and study details are found in the previous publications [4, 5, 22-24]. Briefly, breast cancer patients with lymph node-negative (N0), stage I and IIA tumours were randomised to whole-breast RT (tangential opposed fields of 4-6 MV photons, 48-54 Gy in 24-27 fractions to the remaining breast parenchyma) or no RT after breast-conserving surgery from 1991 to 1997. Administration of systemic adjuvant treatment was according to regional guidelines of the time; $6 \%$ of patients had endocrine treatment only, $1 \%$ chemotherapy only, and $1 \%$ combined endocrine treatment and chemotherapy. The median follow-up times for event-free patients were 15.2 years (IBTR), 15.2 years (any breast cancer recurrence), 20.1 years (BCD) for the indicated endpoint. A flow diagram of the SweBCG91-RT trial is shown in Fig. 1.

\section{TMA construction}

Tumour tissue was collected from formalin-fixed, paraffin-embedded blocks of the primary tumours from 1004 of the original 1178 randomised patients. The material includes 140 surgically treated IBTRs from patients with a primary tumour available in the TMA for matching.
TMA construction was in a semi-automated TMA arrayer (Pathology Devices, Westminster, MD) by extraction of two 1.0-mm cylinders from representative tissue from each tumour block.

\section{Immunohistochemistry (IHC) and evaluation of markers}

IHC staining, evaluation and assessment for ER, progesterone receptor (PgR), human epidermal growth factor receptor 2 (HER2) and Ki-67 were previously performed [24]. Tumours with $1 \%$ or more positive nuclei were considered ER- and PgR-positive, respectively. For dividing tumours between luminal A and B subtypes, a $20 \%$ cut-off for PgR was used. HER2 was scored with IHC as $0,1+, 2+$ or $3+$ and with silver in situ hybridisation and considered positive if $3+$ and/or amplified. Ki- 67 scoring was according to guidelines [25], the cut-off was $10 \%$ positive cells resulting in $27 \%$ of tumours being $\mathrm{Ki}-67$ high [24]. Histologic grade was previously evaluated as described by Elston and Ellis [26]. HIF-1 a IHC was performed as previously described [17]. Briefly, IHC was performed on 4 $\mu \mathrm{m}$ sections of formalin-fixed paraffin-embedded sections (Autostainer Plus, Dako) according to the manufacturer's protocol. A monoclonal antibody recognising HIF-1a (BD610959, Becton Dickinson) diluted 1:50 was employed. Two experienced evaluators blinded to patient treatment, outcome, and tumour characteristics (Kristina Lövgren and Annika Jögi) independently assessed IHC staining for HIF-1a. Each TMA-core was semiquantitatively scored for IHC-staining intensity, 0 (negative), 1 (weak), 2 (moderate) and 3 (intense) and quantitatively scored for proportion positive cancer cells. Proportion score 0 represented less than $1 \%$ positive cells, 1: $1-10 \%$, 2: $11-50 \%$, and 3: $51-100 \%$. Based on IHC intensity and proportion of positive cells each tumour sample was grouped as negative (less than $1 \%$ positive cells or $1-9 \%$ cells with intensity $\leq 1$, Supplemental Fig. 1 A), low ( $1-9 \%$ of cells with intensity $\geq 2$ or $\geq 10 \%$ of cells with intensity 1 , Supplemental Fig. 1B) or high ( $\geq 10 \%$ of cells with intensity $\geq 2$, Supplemental Fig. 1C). In case of discrepant staining between the two cores from the same tumour, the highest score was used. Cases (13\%) with differing results between the viewers were re-evaluated in consensus. Only 60 tumours (6\%) fell into the low-category whereas 227 (23\%) fell into the high-category (Table 1). Due to this skew distribution, the samples of the two positive categories were merged into one HIF-1a positive group, as previously described [17]. Although not postulated in the evaluation criteria, all positive cancer cells had nuclear HIF-1a IHC-signal and very few, 
Table 1. Patient and tumour characteristics in $985 \mathrm{T1}-2 \mathrm{NOMO}$ breast cancer patients randomised to postoperative RT or no RT after breast-conserving surgery, stained for HIF-1 $\alpha$.

\begin{tabular}{|c|c|c|c|c|c|}
\hline & \multirow[t]{2}{*}{ Total } & \multicolumn{3}{|c|}{ HIF-1a immunoreactivity } & \multirow[t]{3}{*}{$p$} \\
\hline & & Negative (\%) & Low (\%) & High (\%) & \\
\hline & 985 & $698(70.9)$ & $60(6.1)$ & $227(23.0)$ & \\
\hline$\leq 49$ & 192 & $137(71.4)$ & $15(7.8)$ & $40(20.8)$ & \multirow[t]{3}{*}{$0.80^{a}$} \\
\hline $50-59$ & 300 & $210(70.0)$ & $18(6.0)$ & $72(24.0)$ & \\
\hline $60-69$ & 375 & $267(71.2)$ & $22(5.9)$ & $86(22.9)$ & \\
\hline Premenopausal & 196 & $137(69.9)$ & $17(8.7)$ & $42(21.4)$ & \multirow[t]{3}{*}{$0.26^{\mathrm{b}}$} \\
\hline Postmenopausal & 765 & $541(70.7)$ & $43(5.6)$ & $181(23.7)$ & \\
\hline Missing & 24 & 20 & 0 & 4 & \\
\hline \multicolumn{6}{|c|}{ Tumour size $($ median $=12 \mathrm{~mm})$} \\
\hline Tumour $>20 \mathrm{~mm}$ & 841 & $604(71.8)$ & $49(5.8)$ & $188(22.4)$ & $0.37^{b}$ \\
\hline ER-positive & 858 & $642(74.8)$ & $49(5.7)$ & $167(19.5)$ & \\
\hline Missing & 27 & 16 & 3 & 8 & \\
\hline PgR-negative & 253 & $154(60.9)$ & $16(6.3)$ & $83(32.8)$ & $<0.0001^{b}$ \\
\hline PgR-positive & 705 & $528(74.9)$ & $41(5.8)$ & $136(19.3)$ & \\
\hline Missing & 27 & 16 & 3 & 8 & \\
\hline HER2-negative & 889 & $645(72.6)$ & $52(5.8)$ & $192(21.6)$ & $0.001^{c}$ \\
\hline HER2-positive & 64 & $33(51.6)$ & $5(7.8)$ & $26(40.6)$ & \\
\hline Missing & 32 & 20 & 3 & 9 & \\
\hline Ki-67 low & 714 & $550(77.0)$ & $46(6.5)$ & $118(16.5)$ & $<0.0001^{2}$ \\
\hline Ki-67 high & 244 & $132(54.1)$ & $11(4.5)$ & $101(41.4)$ & \\
\hline Luminal B (HER2-) & 257 & $181(70.4)$ & $13(5.1)$ & $63(24.5)$ & \\
\hline HER2+ & 64 & $33(51.6)$ & $5(7.8)$ & $26(40.6)$ & \\
\hline Triple negative & 80 & $33(41.3)$ & $5(6.3)$ & $42(52.5)$ & \\
\hline Missing & 32 & 20 & 3 & 9 & \\
\hline No RT & 509 & 349 (68.6) & $34(6.7)$ & $126(24.7)$ & $0.26^{b}$ \\
\hline RT & 476 & $349(73.3)$ & $26(5.5)$ & $101(21.2)$ & \\
\hline Other treatments & & & & & $0.11^{\mathrm{b}}$ \\
\hline Chemotherapy & 9 & $7(77.8)$ & $0(0)$ & $2(22.2)$ & \\
\hline Endocrine & 63 & $43(68.3)$ & $6(9.5)$ & $14(22.2)$ & \\
\hline Chemo + endocrine & 8 & $2(25.0)$ & $1(12.5)$ & $5(62.5)$ & \\
\hline No other treatment & 905 & $646(71.4)$ & $53(5.8)$ & $206(22.8)$ & \\
\hline
\end{tabular}

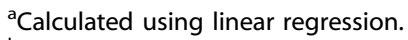

${ }^{\mathrm{b}}$ Calculated using chi-squared test.

${ }^{\text {c} C a l c u l a t e d ~ u s i n g ~ F i s h e r ' s ~ e x a c t ~ t e s t . ~}$

in addition, had cytoplasmic staining, as previously demonstrated [17]. We recently published positive and negative controls for HIF-1a immunostaining on cell lines and a similar breast cancer TMA-material of patients with contralateral tumours [17].

\section{Tumour subtyping}

The tumours were, as previously reported [24], subtyped according to the St Gallen International Breast Cancer Conference (2013) Expert Panel [27] as luminal A-like (ER-positive, PgR-high, HER2-negative, and Ki-67 low), 
luminal B-like (ER-positive, PgR-low and/or Ki-67 high, and HER2-negative), HER2-positive (HER2-positive, any ER or PgR status, any Ki-67 expression), and triple negative (ER-negative, PgR-negative, HER2-negative, any Ki-67). The HER2-positive group thus included both luminal and non-luminal tumours due to group size.

\section{Gene-expression analysis}

Gene-expression analysis of this trial material was previously described [28]. In brief, RNA was extracted from the 922 available paraffin-fixed patient tumour samples. Patient and tumour characteristics were similar in the excluded and analysed tumours. RNA was extracted and hybridised (GeneChip Human Exon 1.0 ST microarray, Thermo Fisher) in a Clinical Laboratory Improvement Amendments certified laboratory (Decipher Biosciences). Samples from 766 primary tumours passed the quality control of RNA, CDNA, and microarray analysis (Gene-expression Omnibus
GSE119295). Single Channel Array Normalisation was used for geneexpression data normalisation [29].

\section{Scoring of hypoxia-related expression signatures from the literature}

Eleven previously published hypoxia-related gene-expression signatures, here referred to as the name of the first author of the publication, were identified from the literature. The signatures Buffa*, Buffa reduced* [30], Denko [31], Elvidge [32], Hu [33], Mense [34], Sorensen [35], and Winter* [36] were selected from a review by Harris et al [20]. Signatures marked by * are related and derived from "Winter", where in brief, genes co-expressed with classical hypoxia-driven genes were chosen and tested in clinical tumour samples, including breast cancer [36]. The signatures from Denko, Elvidge, Mense, and Sorensen were extracted from in vitro hypoxia (1\% oxygen) treated human cells. The Hu signature comprises 13 genes

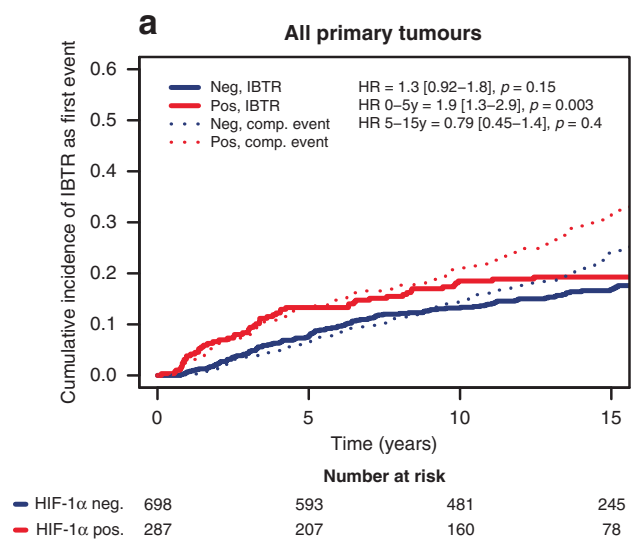

b

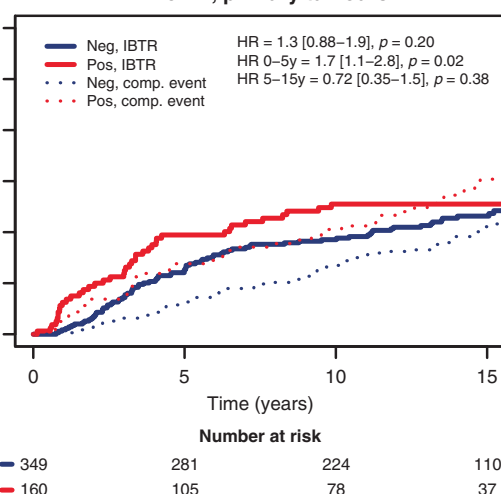

c

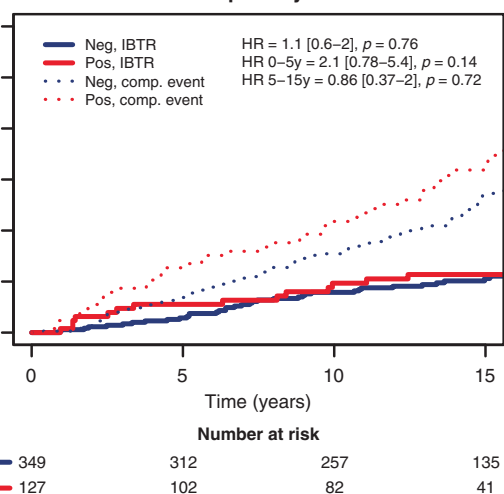

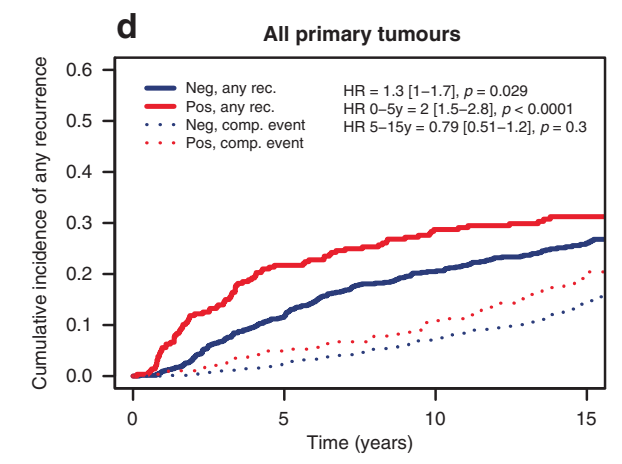

- HIF-1 $\alpha$ neg. 698

- HIF-1 $\alpha$ pos. 287

$$
\mathbf{g}
$$

g

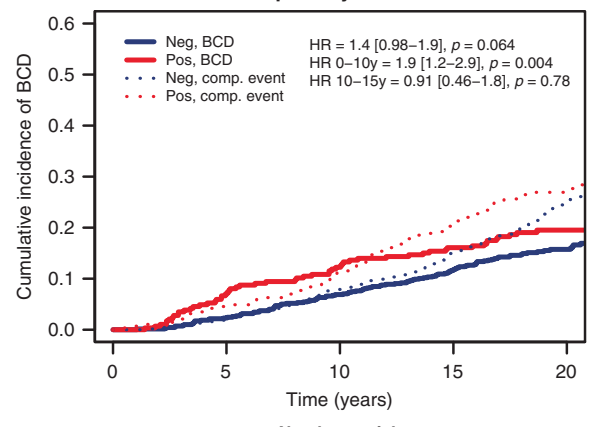

Number at risk

- HIF-1 $\alpha$ neg. 697

- HIF-1 $1 \alpha$ pos. 287 e

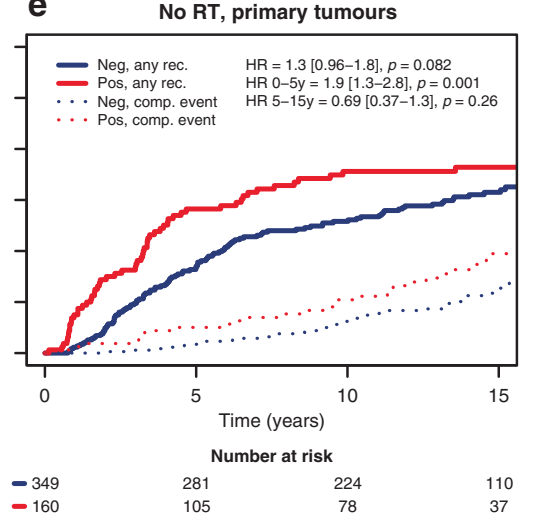

h

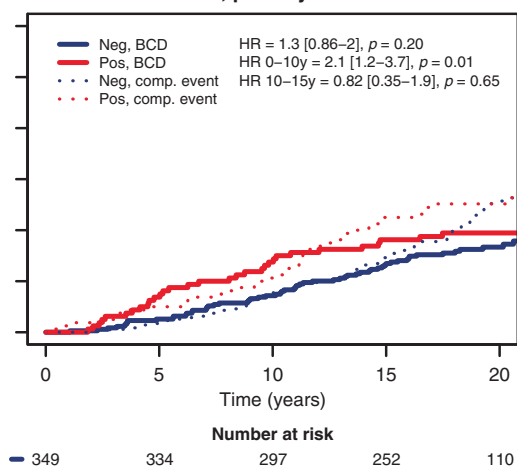

f

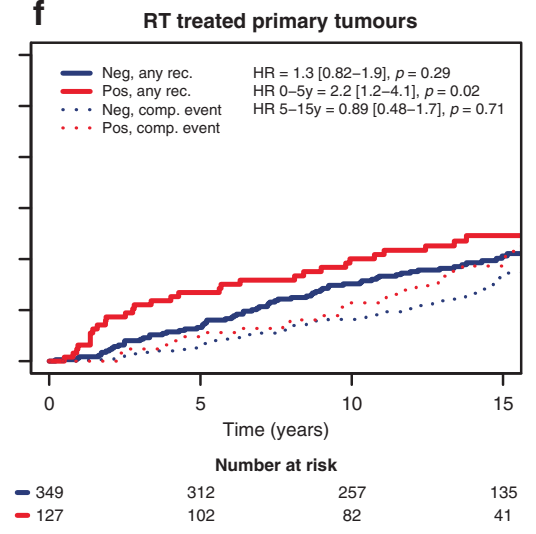

i

RT treated primary tumours

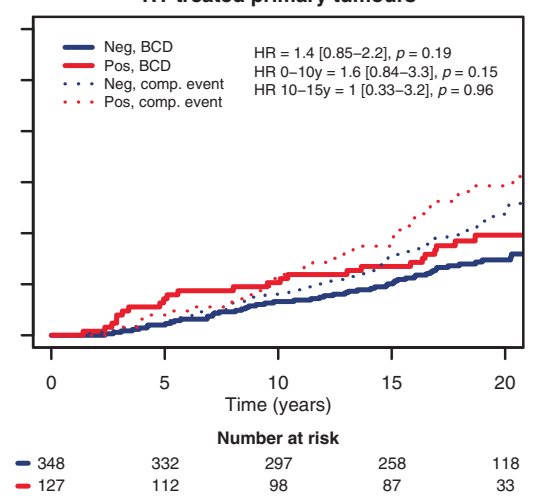

Fig. 2 Higher risk of recurrence and BCD in patients with a HIF-1a positive primary tumour. Cumulative incidence of IBTR after surgery of the primary tumour $(\mathbf{a}-\mathbf{c})$, any recurrences $(\mathbf{d}-\mathbf{f})$, and BCD ( $\mathbf{g}-\mathbf{i})$ in 985 T1-2NOM0 breast cancer patients randomised to RT (c, f, $\mathbf{g})$ or no RT $(\mathbf{b}, \mathbf{e}, \mathbf{h})$ after breast-conserving surgery in patients with HIF-1 $\alpha$ negative (blue line) and HIF-1 $\alpha$ positive (red line) primary tumour. 
referred to as a VEGF-profile, 8 of the genes having a hypoxia-responsive element that can bind HIF in their promoters. The Farmer signature was based on GSEA hypoxia genes in breast cancer cells with apocrine phenotype, i.e. not based on actual hypoxic exposure [37]. The signature referred to as "Yang" was the most recently published, and based on in vitro hypoxic treatment of prostate cancer cell lines and validated in several publicly available prostate and bladder cancer materials [38]. The Hallmark of Cancer hypoxia gene signature was included since it has been widely used in literature. It is based on several sources including the Winter, Elvidge, Mense gene-expression signatures mentioned above, and includes genes regulated by the von Hippel-Lindau factor and several metabolic pathways such as the glycolysis.

Individual hypoxia scores for primary tumours in SweBCG91-RT were calculated using the singscore package in R [39], or as described by the authors. Scores were considered as continuous variables or combined into a binary variable of high or low, with the $4^{\text {th }}$ quartile being defined as high, and quartiles 1-3 as low, thus giving a similar proportion of hypoxic tumours as detected by HIF-1 a IHC (29\%). Interaction tests were performed with scores as a continuous variable to avoid introduction of bias from cut-off. If any gene ID was not matched in our expression set, synonym gene names were retrieved using the $\mathrm{R}$ package HGNChelper [40]. If one signature gene ID corresponded to multiple synonym IDs, a search was conducted on GeneCards database of human genes [41] to select the matching synonym. Genes were excluded if an ID match was not identified.

\section{Statistical methods}

All statistical analyses were performed with $\mathrm{R}$ (3.5.2). The primary endpoint was IBTR in any quadrant of the ipsilateral breast, though $90 \%$ were located in the same quadrant as the primary tumour, as first event within 5 years [22]. Other recurrences and death by any cause were competing events. Secondary endpoints were any breast cancer recurrence within 5 years, (including IBTR, regional and distant recurrence, but not contralateral breast cancer), with death by any cause without recurrence as competing event, and $\mathrm{BCD}$, with death by other cause as competing event. For the descriptive, exploratory analysis of the relationship between HIF-1a in IBTR and BCD, the start point was the date of surgery for the IBTR, and the endpoint was BCD. Cumulative incidence with competing events was displayed graphically using the $\mathrm{R}$ package $\mathrm{cmprisk}$ [42] and presented with hazard ratio (HR) and 95\% confidence interval calculated using causespecific Cox proportional hazards model. The interactions between the benefit of RT and markers of hypoxia were evaluated using cause-specific Cox proportional hazards model with an interaction term. The proportional hazards assumption was checked graphically and tested with Schoenfeld residuals [43]. As seen before in this cohort [24], HRs over the full follow-up were generally non-proportional, thus we present estimations of $H R$ in intervals $(0-5$ years, $5-15$ years, and $>15$ years for IBTR and any recurrence as first event, or $0-10$ years, 10-15 years, and $>15$ years for $B C D$ as first event) along with the HR for the full follow-up. All HR estimations should be interpreted as an average over the studied time interval. Associations between HIF-1a and other patient and tumour characteristics were assessed using the chi-squared test or Fisher's exact test or tested for trend using linear regression. Statistical significance was defined as $p<$ 0.05 , but due to the multiple hypothesis testing performed in this study, the interpretation of $p$ as level of evidence for or against the null hypothesis should be careful.

\section{RESULTS}

\section{HIF-1a in primary breast tumours}

Of the 1004 tumours available in the TMA, 985 were successfully stained and evaluated for HIF-1a (Fig. 1), where 698 (71\%) were HIF-1a negative. Primary tumours with IHC-staining positive for HIF-1a were similarly distributed in the RT and non-RT groups (27\% and $31 \%$, respectively). Patient and tumour characteristics are described in Table 1. Tumour HIF-1a status correlated to histological grade, with a higher frequency of HIF-1a positivity among high-grade tumours $(p<0.0001)$. Furthermore, HIF-1a positivity was associated with cell proliferation in that it correlated to high Ki-67 $(p<0.0001)$. A considerably higher proportion of ERnegative tumours, compared to ER-positive tumours, were HIF-1a positive $(60 \%$ vs $25 \%, p<0.0001)$. Luminal A-like tumours were the largest subgroup with 552 tumours and $22 \%$ of these were HIF-1a positive, while luminal B tumours had a $30 \%$ frequency of HIF-1a positivity (76 of 257 , Table 1 ).

\section{Higher risk of recurrence and BCD in patients with HIF-1a positive primary tumours}

Patients with a HIF-1a positive primary tumour had an increased incidence of IBTR as a first event within 5 years compared to patients with a HIF-1a negative primary tumour both in the total patient population $\left(\mathrm{HR}_{0-5}\right.$ yrs $=1.9$ [1.3-2.9], $p=0.003$, Fig. $2 \mathrm{a}$ and Table 2$)$ and among patients that did not receive $\mathrm{RT}\left(\mathrm{HR}_{0-5}\right.$ yrs $=$ 1.7 [1.1-2.8], $p=0.02$, Fig. $2 \mathrm{~b}$ and Table 2). The higher occurrence of IBTR in patients that had HIF-1a positive primary tumours was apparent in both ER-positive and -negative disease (Supplemental Fig. 2). Patients that received RT suffered less IBTR, with no difference between HIF-1a positive and negative groups (Fig. 2c). In multivariable analysis adjusted for patient age, tumour size, tumour subtype (St Gallen), and systemic adjuvant therapy, the increased risk for IBTR in the HIF-1a positive group remained an independent risk factor in the total patient population $\left(\mathrm{HR}_{\text {adjusted }}=1.8\right.$ [1.1-2.8], $p=0.01$, Table 2$)$.

In analyses of any recurrences in the whole patient material as well as in the non-irradiated group, HIF-1a primary tumour

Table 2. Uni- and multivariable analysis of the hazard of HIF-1 $\alpha$ (positive vs negative) in relationship to IBTR during the first 5 years after the primary tumour, any recurrences during the first 5 years after the primary tumour, and BCD during the first 10 years after the primary tumour in breast cancer patients randomised to receive RT or no RT after breast-conserving surgery.

\begin{tabular}{|c|c|c|c|c|c|c|}
\hline \multirow[t]{2}{*}{ All patients } & \multicolumn{3}{|c|}{ Univariable analysis } & \multicolumn{3}{|c|}{ Multivariable analysis } \\
\hline & HR (95\% Cl) & $p$ & $n$ (event) & HR (95\% Cl) & $p$ & $n$ (event) \\
\hline \multicolumn{7}{|c|}{ IBTR (0-5 years) } \\
\hline No RT & $1.7(1.1-2.8)$ & 0.02 & $509(75)$ & $1.6(0.97-2.7)$ & 0.065 & $492(68)$ \\
\hline RT & $2.1(0.78-5.4)$ & 0.14 & $476(17)$ & $2.1(0.78-5.8)$ & 0.14 & $456(17)$ \\
\hline \multicolumn{7}{|c|}{ Any recurrence ( $0-5$ years) } \\
\hline No RT & $1.9(1.3-2.8)$ & 0.001 & 509 (104) & $1.6(1-2.5)$ & 0.03 & $492(97)$ \\
\hline RT & $2.2(1.2-4.1)$ & 0.02 & $476(40)$ & $1.7(0.89-3.2)$ & 0.11 & $456(40)$ \\
\hline \multicolumn{7}{|c|}{ BCD (0-10 years) } \\
\hline All patients & $1.9(1.2-2.9)$ & 0.004 & $985(83)$ & $1.5(0.93-2.3)$ & 0.097 & $948(82)$ \\
\hline No RT & $2.1(1.2-3.7)$ & 0.01 & $509(47)$ & $1.5(0.82-2.9)$ & 0.18 & $492(46)$ \\
\hline
\end{tabular}


positivity was associated with an increase in early recurrences $\left(\mathrm{HR}_{0-5}\right.$ years 2 , [1.5-2.8], $p=0.0001$ and $\mathrm{HR}_{0-5}$ years $1.9,[1.3-2.8]$, $p=0.001$, Fig. $2 \mathrm{~d}$, e and Table 2), with a similar pattern in patients with ER-positive and -negative tumours (Supplemental Fig. 2). Postoperative RT led to an overall decrease in any recurrence, however, there were still a higher number of recurrences in patients with a HIF-1a positive primary tumour (Fig. $2 f$ and Table 2).

There was a higher occurrence of BCD within 10 years of surgery in patients with HIF-1a positive primary tumour in the entire study population and in patients that did not receive RT $\left(\mathrm{HR}_{0-10}\right.$ years 1.9 [1.2-2.9], $p=0.004$, and $\mathrm{HR}_{0-10}$ years 2.1 [1.2-3.7], $p=0.01$ Fig. $2 \mathrm{~g}, \mathrm{~h}$ and Table 2), while this difference diminished after RT (Fig. 2I). In patients with ER-negative tumours, with a high frequency of HIF-1a positive primary tumours (60\%), BCD within 10 years was higher compared to ER-positive tumours irrespective of primary tumour HIF-1a status (Supplemental Fig. 2e, f).

\section{Preserved benefit of RT in patients with HIF-1a positive primary tumours}

Taking all primary tumours into account, patients receiving RT had a distinct reduction of IBTR within 5 years $\left(\mathrm{HR}_{0-5 y e a r s} 0.23\right.$, [0.13-0.39], $p<0.0001$; Fig. 3a and Table 3), and the full follow-up ( $\mathrm{HR}_{\text {full Fu }} 0.42$, [0.3-0.58], $p<0.0001$; Fig. 3a). Dividing the patients into those with HIF-1a negative and positive primary tumours, there was a similar reduction in IBTR with RT in the two groups (test for
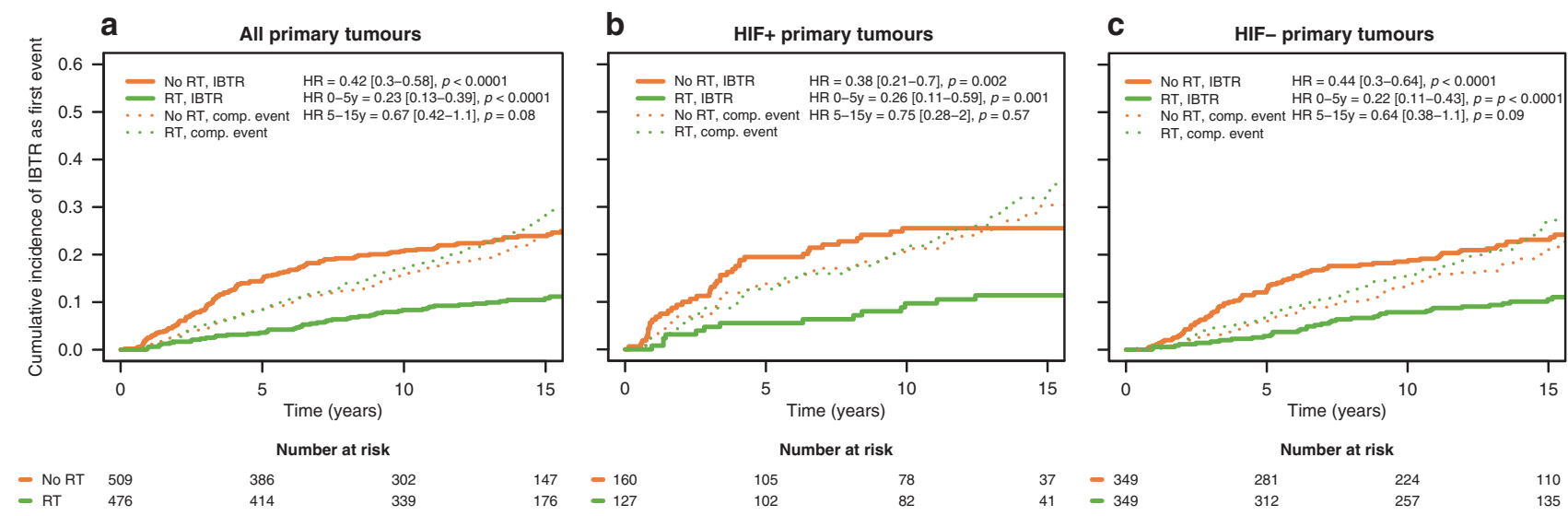

-349
-349
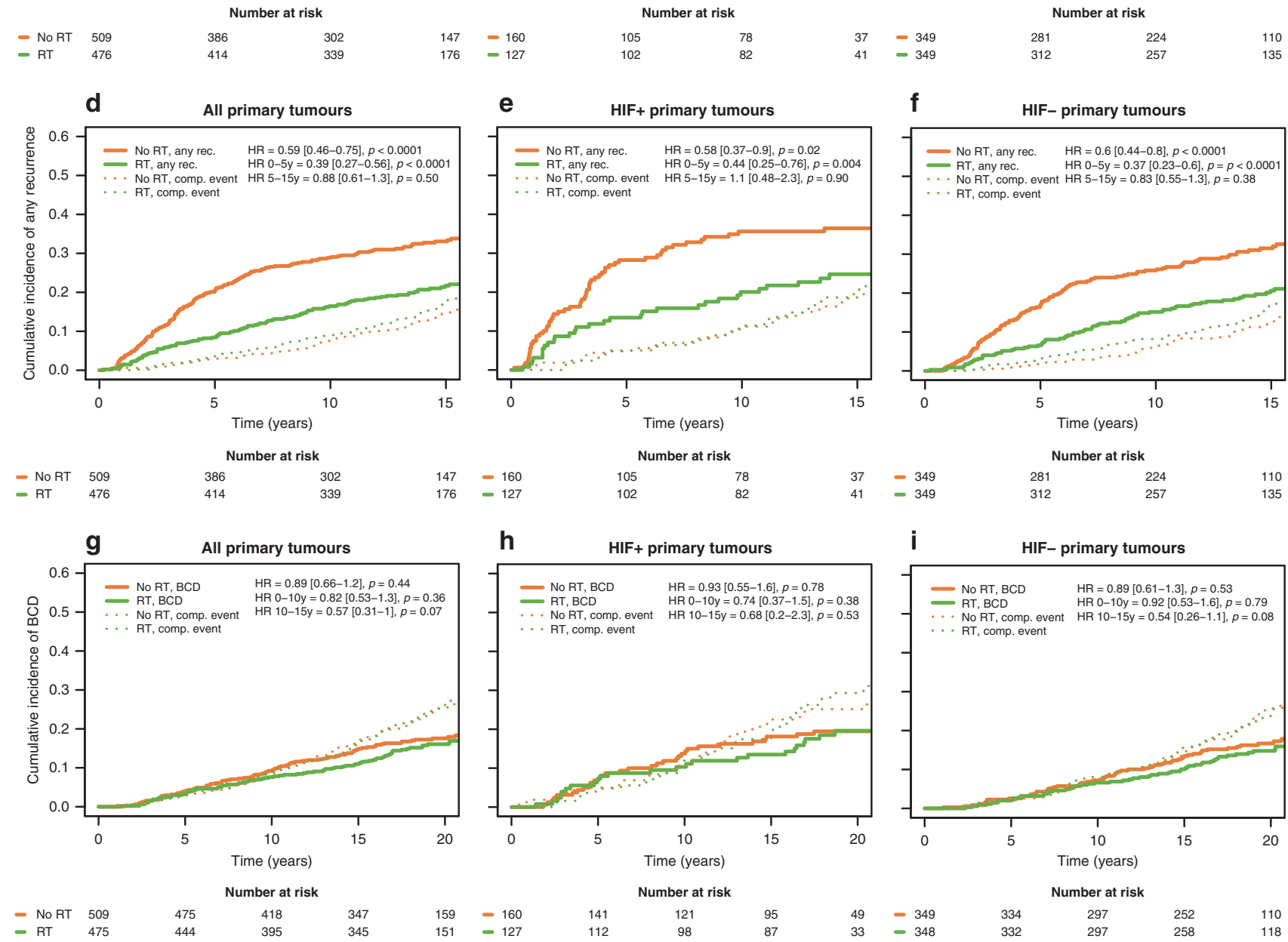

i HIF- primary tumours

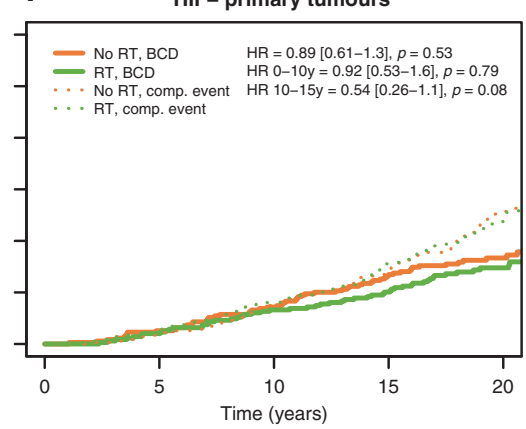

$\begin{array}{lllllll}\text { - No RT } & 509 & 475 & 418 & 347 & 159 & -160 \\ \text { - RT } & 475 & 444 & 395 & 345 & 151 & -127\end{array}$

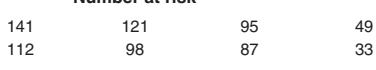

-349
-348

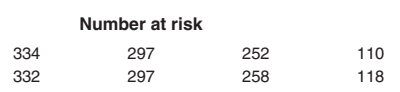

Fig. 3 Reduction in recurrence with RT was independent of primary tumour HIF-a status. Cumulative incidence of IBTR after surgery of the primary tumour $(\mathbf{a}-\mathbf{c})$, any recurrences $(\mathbf{d}-\mathbf{f})$ as first event, and BCD $(\mathbf{g}-\mathbf{i})$ in 985 T1-2N0M0 breast cancer patients randomised to RT (green line) or no RT (orange line) after breast-conserving surgery for all primary tumours (a, d, g), HIF-1 $\alpha$ positive primary tumours (b, e, $\mathbf{h})$, and HIF- $1 \alpha$ negative primary tumours $(\mathbf{c}, \mathbf{f}, \mathbf{i})$. 
Table 3. Uni- and multivariable analysis of the benefit of RT in relationship to IBTR during the first 5 years after the primary tumour, any recurrences during the first 5 years after the primary tumour, and $B C D$ during the first 10 years after the primary tumour in breast cancer patients randomised to receive $\mathrm{RT}$ or no RT after breast-conserving surgery.

\begin{tabular}{|c|c|c|c|c|c|c|}
\hline & \multicolumn{3}{|c|}{ Univariable analysis } & \multicolumn{3}{|c|}{ Multivariable analysis } \\
\hline & HR (95\% Cl) & $p$ & $n$ (event) & HR $(95 \% \mathrm{Cl})$ & $p$ & $n$ (event) \\
\hline \multicolumn{7}{|l|}{ IBTR (0-5 years) } \\
\hline HIF- $1 \alpha+$ & $0.26(0.12-0.59)$ & 0.001 & $287(38)$ & $0.30(0.12-0.69)$ & 0.005 & $272(35)$ \\
\hline HIF-1 $1 \alpha-$ & $0.21(0.11-0.43)$ & $<0.0001$ & $698(54)$ & $0.22(0.11-0.46)$ & $<0.0001$ & $676(50)$ \\
\hline \multicolumn{7}{|c|}{ Any recurrence (0-5 years) } \\
\hline HIF- $1 \alpha+$ & $0.44(0.25-0.76)$ & 0.003 & $287(62)$ & $0.48(0.27-0.86)$ & 0.01 & $272(59)$ \\
\hline HIF-1 $\alpha-$ & $0.37(0.23-0.6)$ & $<0.0001$ & $698(82)$ & $0.37(0.23-0.62)$ & $<0.0001$ & $676(78)$ \\
\hline \multicolumn{7}{|c|}{$B C D(0-10$ years $)$} \\
\hline All patients & $0.82(0.53-1.3)$ & 0.36 & $985(83)$ & $0.87(0.56-1.4)$ & 0.54 & $948(82)$ \\
\hline HIF- $1 \alpha+$ & $0.74(0.37-1.5)$ & 0.38 & $287(35)$ & $0.84(0.42-1.7)$ & 0.62 & $272(35)$ \\
\hline
\end{tabular}

interaction $_{0-5 \text { years }} p=0.90$, test for interaction full Fu $p=0.66$, Fig. $3 \mathrm{~b}$, $\mathrm{c}$ and Table 3). The incidence for any recurrences within 5 years, and full follow-up, was also reduced in patients that had received RT $\left(\mathrm{HR}_{0-5 y e a r s} 0.39,[0.27-0.56], p<0.0001\right.$, and $\mathrm{HR}_{\text {full Fu }} 0.59$, [0.46-0.75], $p<0.0001$; Fig. $3 \mathrm{~d}$ and Table 3), and this effect of RT on recurrence was independent of HIF-1a status (test for interaction ${ }_{0-5}$ years $p=$ 0.70 , test for interaction full fu $p=0.79$, Fig. $3 \mathrm{e}, \mathrm{f}$ and Table 3 ). In the present study, there was no statistically significant effect of RT on the incidence of $\mathrm{BCD}\left(\mathrm{HR}_{0-10}\right.$ years 0.82 [0.53-1.3], $p=0.36$, Table 3), and this was unaffected by HIF-1a status (test for interaction $0-10$ years $p=0.54$, test for interaction full fu $p=0.80$, Fig. $3 g-i$, Table 3 ).

\section{HIF-1a in IBTR and relation to outcome}

For a fraction of the cohort, IHC staining of HIF-1a in matched primary and IBTR tumour material was available $(n=119)$. HIF-1a positive IBTR was more prevalent among patients that had a HIF1a positive, compared to negative, primary tumour $(61 \%$ vs $27 \%$, $p<0.001$ : Fig. 4a). In line with this, when considering HIF-1a IHC on three levels (negative, low and high), the IBTRs most often had the same HIF-1 a staining intensity as their corresponding primary tumour $(65 \%, n=75)$, while $21 \%(n=24)$ of the IBTRs had increased intensity, and $14 \%(n=16)$ had decreased HIF-1a intensity. Addressing the prognostic relevance of HIF-1a expression in IBTR, we found that HIF-1a positivity in IBTR was associated with an increased risk of $B C D\left(\mathrm{HR}_{\text {fullFu }} 2.6\right.$ [1.3-5.0], $p=0.007$; Fig. 4b).

\section{Hypoxic gene-expression signatures and relation to outcome and benefit of RT treatment}

There was a concordance between HIF-1 a IHC signal and HIF-1a mRNA-expression levels ( $r$ o $=0.40, p<0.0001$, Fig. 4c). However, there was no association between high HIF-1a mRNA expression (highest quartile) and breast cancer recurrence or survival (data not shown). In general, the hypoxic signature scores exhibited a high positive correlation with HIF-1a positive IHC status, with the Mense hypoxia score being the only exception (Fig. 5a). The strongest correlations to HIF-1a positive IHC were observed for "Buffa" (rho $=0.26, p<0.0001)$, "Farmer" (rho $=0.27, p<0.0001$ ), and "Hu" (rho $=0.26, p<0.0001$, Fig. 5a). The calculated hypoxia scores of most gene signatures correlated strongly (Fig. 5b). The Mense hypoxia score did not correlate with the majority of other hypoxia scores, whereas the Yang signature had a clear negative correlation to several other hypoxia scores. Although most hypoxia scores correlated strongly, the gene overlaps were modest with a relatively low number of shared genes (Fig. $5 \mathrm{C}$ ). Nine genes were present in $\geq 5$ signatures: ADM, NDRG1, SLC2A1, VEGFA, ALDOA, IGFBP3, LDHA, P4HA1 and TPI1.

To address the hypothesis that benefit of RT is affected by a hypoxic tumour microenvironment, we evaluated the benefit of RT in relation to gene expression of the hypoxic gene-expression signatures. The cohort was stratified based on the scores of each hypoxia signature and tested for statistical interaction between benefit of RT and hypoxia scores with respect to outcome (Fig. 5d). Patients had benefit from RT in prevention of early IBTR, regardless of hypoxia scores (Fig. 5d).

Several signature scores associated with an increased incidence of IBTR as a primary event, with the Buffa signatures ("Buffa" $\left.\mathrm{HR}_{5 y r s} 1.5[1.2-1.9], p<0.001\right)$, and "Buffa reduced" $\left(\mathrm{HR}_{5 \mathrm{yrs}} 1.4[1.1-1.8], p=0.002\right)$ and $\mathrm{Hu}$ signature $\left(\mathrm{HR}_{5 \mathrm{yrs}} 1.4\right.$ [1.1-1.7], $p=0.005$ ) being most prognostic for IBTR (Fig. 6a, b and Supplemental Fig. 3). Additionally, some signatures were associated with any recurrence, with the "Buffa reduced" $\left(\mathrm{HR}_{0-5 y r s} 1.5\right.$ [1.3-1.8], $\left.p<0.001\right)$, "Hu" $\left(\mathrm{HR}_{0-5 y r s} 1.5\right.$ [1.2-1.7], $p<0.001)$, and "Winter" ( $\mathrm{HR}_{0-5 y r s} 1.4$ [1.2-1.7], $\left.p<0.001\right)$ being most pronounced (Fig. 6b and Supplemental Fig. 4). Lastly, some signature scores were associated to an increased incidence of BCD (Fig. $6 \mathrm{~b}$ and Supplemental Fig. 5), where the "Buffa reduced" (HR $\mathrm{H}_{0-10 y r s} 1.6$ [1.3-2.1], $\left.p<0.001\right)$, "Yang" $\left(\mathrm{HR}_{0-10 \mathrm{yrs}}\right.$ 1.4 [1.1-1.7], $p=0.004)$ and "Hu" (HR $\mathrm{HR}_{0-10 y r s} 1.5$ [1.2-1.9], $p<$ 0.001 ) were most prominent.

\section{DISCUSSION}

In this study, we address the role of tumour hypoxia, detected by HIF-1a IHC or hypoxic gene-expression signatures, in relation to outcome and benefit of RT in a large, randomised trial of postoperative RT in early breast cancer.

In contrast to our initial hypothesis, we show that breast cancer patients benefit from postoperative RT regarding IBTR, and any recurrence, also when the primary tumour was HIF-1a IHC positive or had high expression of hypoxic gene signatures. We found no effect of postoperative RT on BCD, irrespective of primary tumour HIF-1a status. However, a benefit of postoperative RT in the prevention of BCD has been demonstrated in meta-analyses [3]. Thus, RT directed to the remaining breast tissue was similarly 
a

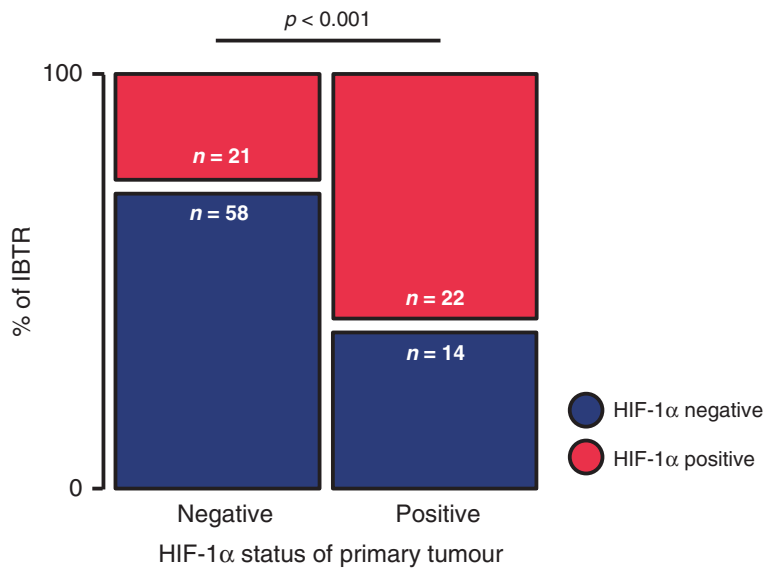

b

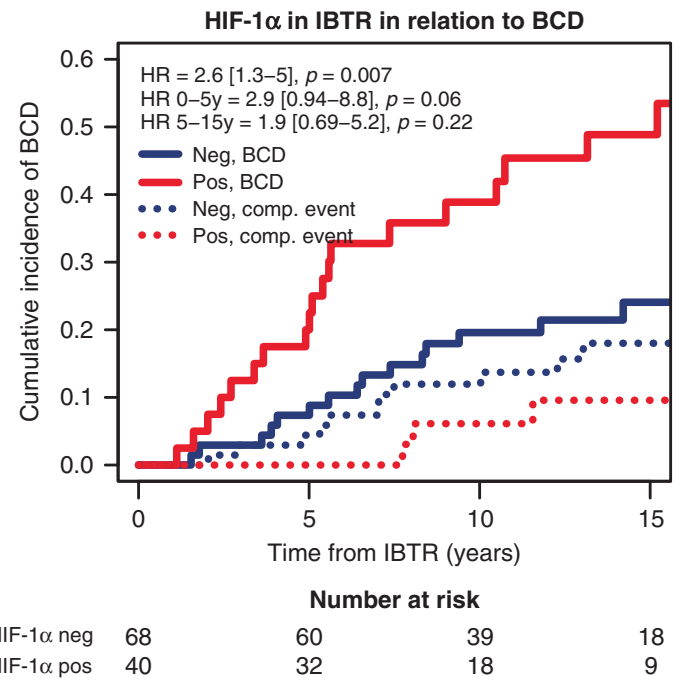

$\begin{array}{ccccc}\text { - HIF-1 } \alpha \text { neg } & 68 & 60 & 39 & 18 \\ \text { - HIF-1 } \alpha \text { pos } & 40 & 32 & 18 & 9\end{array}$

C

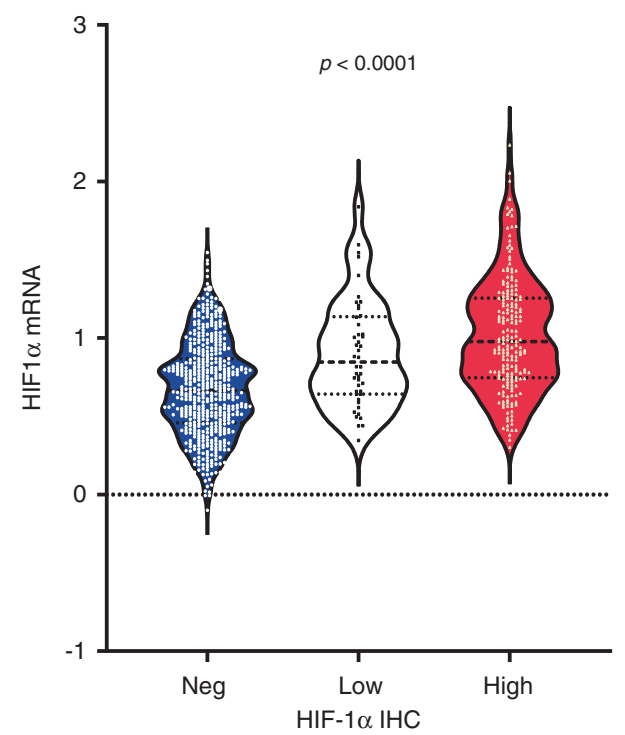

effective on disseminated cancer cells whether these were schooled in a hypoxic or non-hypoxic primary tumour.

For breast cancer, RT is most often given after tumour resection. In cancers that are primarily treated with radiation (e.g. some head and neck cancers and bladder cancers) the
Fig. 4 HIF-1 $\alpha$ and IBTR. Distribution of HIF- $1 \alpha$ positive (red boxes) and negative (blue boxes) IBTRs in relation to primary tumour status, statistically tested using the chi-squared test (a). Cumulative incidence of BCD in relation to HIF- $1 \alpha$ status of the resected IBTR, with the date of surgery for the IBTR as starting point (b), patients with HIF- $1 \alpha$ positive IBTR (red line) compared to those with HIF-1 $\alpha$ negative IBTR (blue line). Time from IBTR resection. Concordance between HIF-1 $\alpha$ IHC and HIF-1a mRNA levels in tumour samples, tested using Spearman's rank test (c), showing HIF-1 $\alpha$ IHC signal in three levels; negative (blue), low (white), and high (red).

hypoxic microenvironment remains and may even be enhanced due to radiation-induced tissue damage. The cells residing in the hypoxic microenvironment may then continue communicating with the microenvironment through the release of growth factors and other signalling molecules in a hypoxia-adapted state, potentially affecting the outcome. This could explain why hypoxia has been associated with RT resistance [44-46], but not in this postoperative study.

Tumour HIF-1a positivity correlated to unfavourable tumour characteristics. Analyses of the non-irradiated patient group, as well as the total study population, showed that patients with HIF1a positive primary tumours were more prone to develop IBTR during the first five years after surgery. Multivariable analysis showed that primary tumour HIF-1a positivity was an independent risk factor for IBTR in the total patient population. In addition, primary tumour HIF-1a positivity correlated to an increase in any recurrence in the whole study population and remained an independent risk factor after adjustment for patient age, tumour subtype, size, and systemic treatment. Primary tumour HIF-1a positivity was also associated with an increase in BCD, but not when adjusted for patient age, tumour subtype, size and systemic treatment. The association between primary tumour HIF-1a positivity and IBTR is, to our knowledge, a novel finding, and in line with previous reports that hypoxia and HIF-1a are associated with distant metastasis and poor prognosis in breast cancer [1618]. Breast tumour hypoxia and HIF-1a-regulated gene expression contribute to aggressive tumour behaviour and seeding of cancer cells with a metastatic capacity $[47,48]$.

We found that most tumour samples from surgically removed IBTRs had the same HIF-1a status as their corresponding primary tumour, indicating that hypoxia and HIF-1a positivity is an inherent tumour trait. Additionally, of 11 hypoxia-related geneexpression signatures from the literature, 10 correlated with HIF1 a protein level, and 5 with an increased risk of IBTR within 5 years after resection of the primary tumour. The presence of a HIF-1apositive IBTR correlated to an increased risk for BCD compared to having a HIF-1a negative IBTR, analysed in relation to time after IBTR-surgery (Fig. 4b).

To specifically address whether ER affects the role of tumour hypoxia, we investigated the hazard of the investigated hypoxia markers in ER-positive and -negative groups separately. We found that primary tumour HIF-1a positivity was a risk factor for IBTR and any recurrence within 5 years after surgery in the ER-positive subgroup as well as in the entire study population. The study included too few patients with ER-negative primary tumour to allow for meaningful multivariable analyses in this subgroup. In this large breast cancer material, we establish that HIF-1a positivity is associated with the tumour subtype. Luminal A tumours have the lowest frequency of HIF-1a positivity, and the frequency of HIF-1a-positivity is then increasing step by step in luminal B, HER2-positive and triple-negative tumours. HIF-1a positivity, thus, has a negative correlation to the distribution of ER expression in the breast cancer subtypes. The ER-negative breast tumours generally have a worse prognosis and a high frequency of HIF-1a-positivity. However, as stated above, within the ER-positive group HIF-1a-positivity remains associated with a 


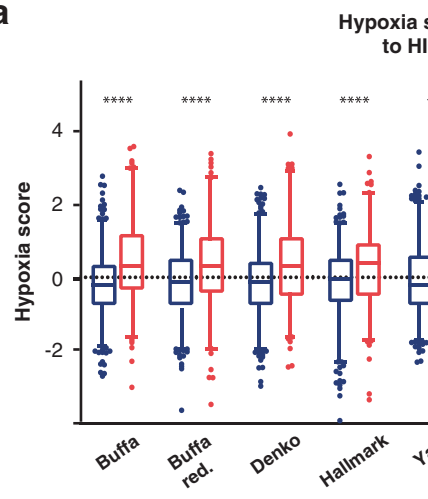

b

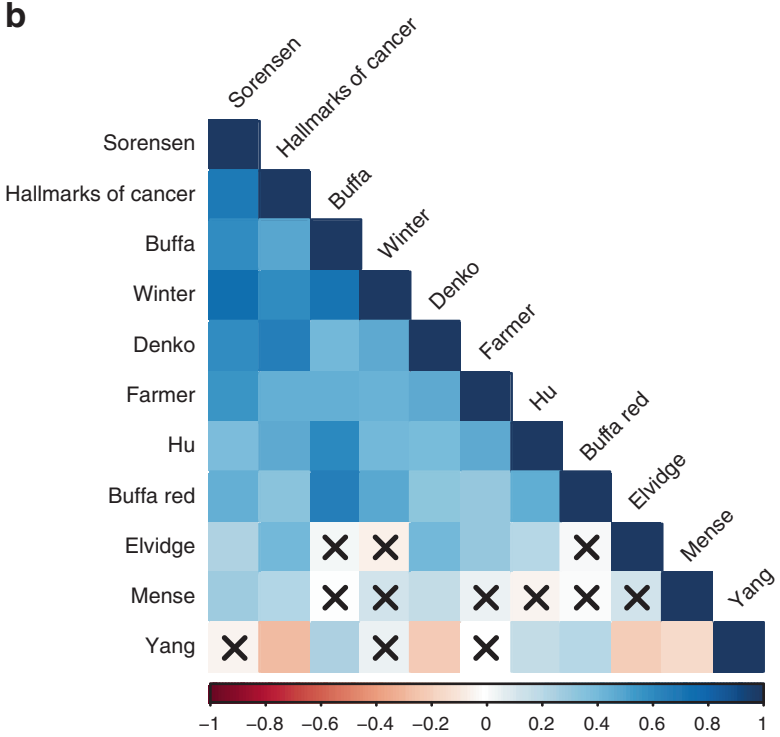

xia signature scores in relation o HIF-1 $\alpha$ immunoreactivity

************

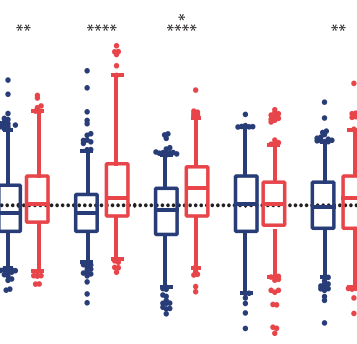

C

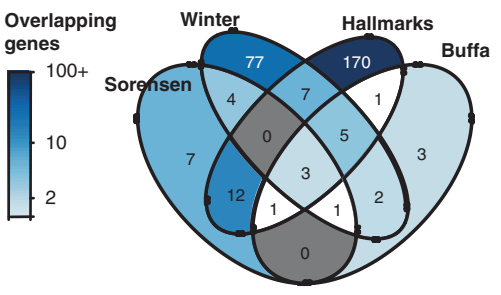

HIF-1 $\alpha$ negative

HIF-1 $\alpha$ positive

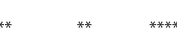

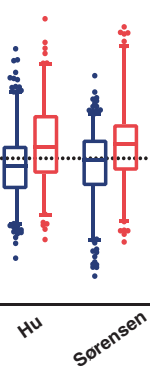

d

Denefit of RT in prevention of IBTR in relation to hypoxia signature scores
Signature score
Buffa high
Buffa low
Buffa red high
Buffa red low
Denko high
Denko low
Elvidge high
Elvidge low
Farmer high
Farmer low
Hallmarks high
Hallmarks low
Hu high
Hu low
Mense high
Mense low
Sorensen high
Sorensen low
Winter high
Winter low
Yang high
Yang low
Full cohort

Fig. 5 Hypoxic gene-expression signatures. Hypoxia signature scores in relation to HIF-1 $\alpha$ IHC status, negative (blue) and positive (red), presented as boxes of the 25th-75th percentiles with whiskers at percentile $2.5-97.5{ }^{*} p<0.05,{ }^{* *} p<0.01,{ }^{* * *} p<0.001,{ }^{* * * *} p<0.0001$ (a). Correlations were tested using Spearman's correlation. Correlation plot of hypoxia signature scores, ordered according to the first principal component order (b). Positive correlations in increasing intensity of blue and negative in red. Crossed squares mark correlations where $p<$ 0.0001 . Venn diagram of gene overlaps in four of the hypoxia signatures between which the scores exhibited the highest correlation (c), darker colour representing higher percentage of overlapping genes. Forest plot presenting the benefit of RT in prevention of IBTR the first 5 years after the primary tumour in relation to hypoxia signature scores (d). The tumours were stratified based on hypoxia scores, where the 4th quartile was defined as high, and quartile 1-3 as low.

worse prognosis. We have previously shown, on the molecular level, that in hypoxic breast cancer cells ER-expression diminishes as HIF-1a accumulate $[17,49]$. It is plausible that, in the generally less proliferative ER-positive tumours, the additive effect of growth factors, cytokines and other effectors induced by HIF-regulated transcription have a relatively greater impact than in ER-negative tumours.

Regulation of HIF-1a is mainly post-translational as described above, but we found that HIF-1a IHC signal correlated to HIF-1a mRNA-expression levels. Albeit, with a great degree of variability, and HIF-1a mRNA-expression did not correlate to tumour characteristics or patient outcome (data not shown). Thus, the need for a hypoxic gene-expression signature remains. To further study the role of tumour hypoxia in relation to patient outcome, we calculated a series of hypoxic scores according to hypoxiarelated gene-expression signatures from the literature for each tumour in the cohort. Eleven literature-derived hypoxia geneexpression signatures [30-38] were analysed in relation to patient outcome. There was a high degree of correlation between several of the signatures, which was anticipated as some were published by associated research groups. The signatures were enriched in genes known to be regulated by HIF. Furthermore, we found that their expression correlated with HIF-1a IHC positivity, indicating that IHC detected transcriptionally active HIF-1a. High expression of most of the analysed hypoxia signatures correlated to a higher incidence of IBTR, any recurrence, and $B C D$, similarly to the pattern seen for HIF-1a IHC positivity. Notably, the Elvidge, Mense and Yang signatures did not correlate to increased occurrence of IBTR and were also among those with the least gene overlap and score correlation with the other signatures (Fig. 5b, c). However, the hallmarks of cancer signature, which had a large overlap with other hypoxic signatures, also did not correlate to increased IBTRs (Fig. 6). None of the hypoxic signatures, similar to HIF-1a IHC, correlated to RT-resistance.

In conclusion, patients with HIF-1a positive primary tumours had a worse outcome with increased recurrences, but these patients still had equal benefit from postoperative RT as patients with a non-hypoxic primary tumour. 


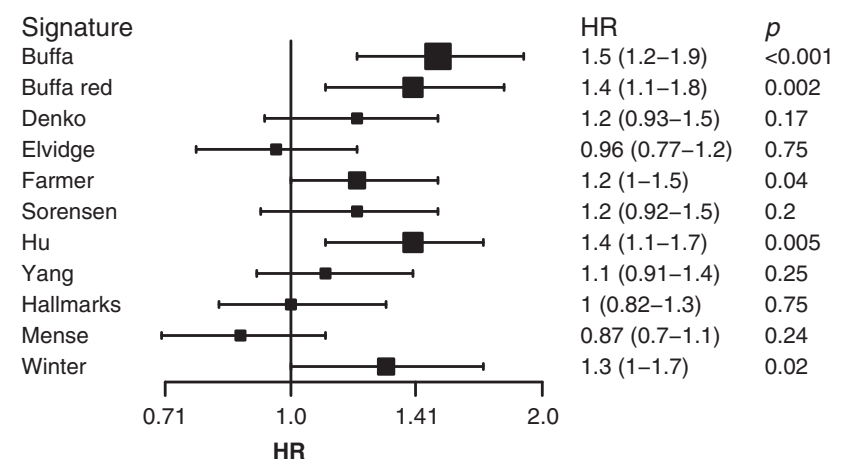

b
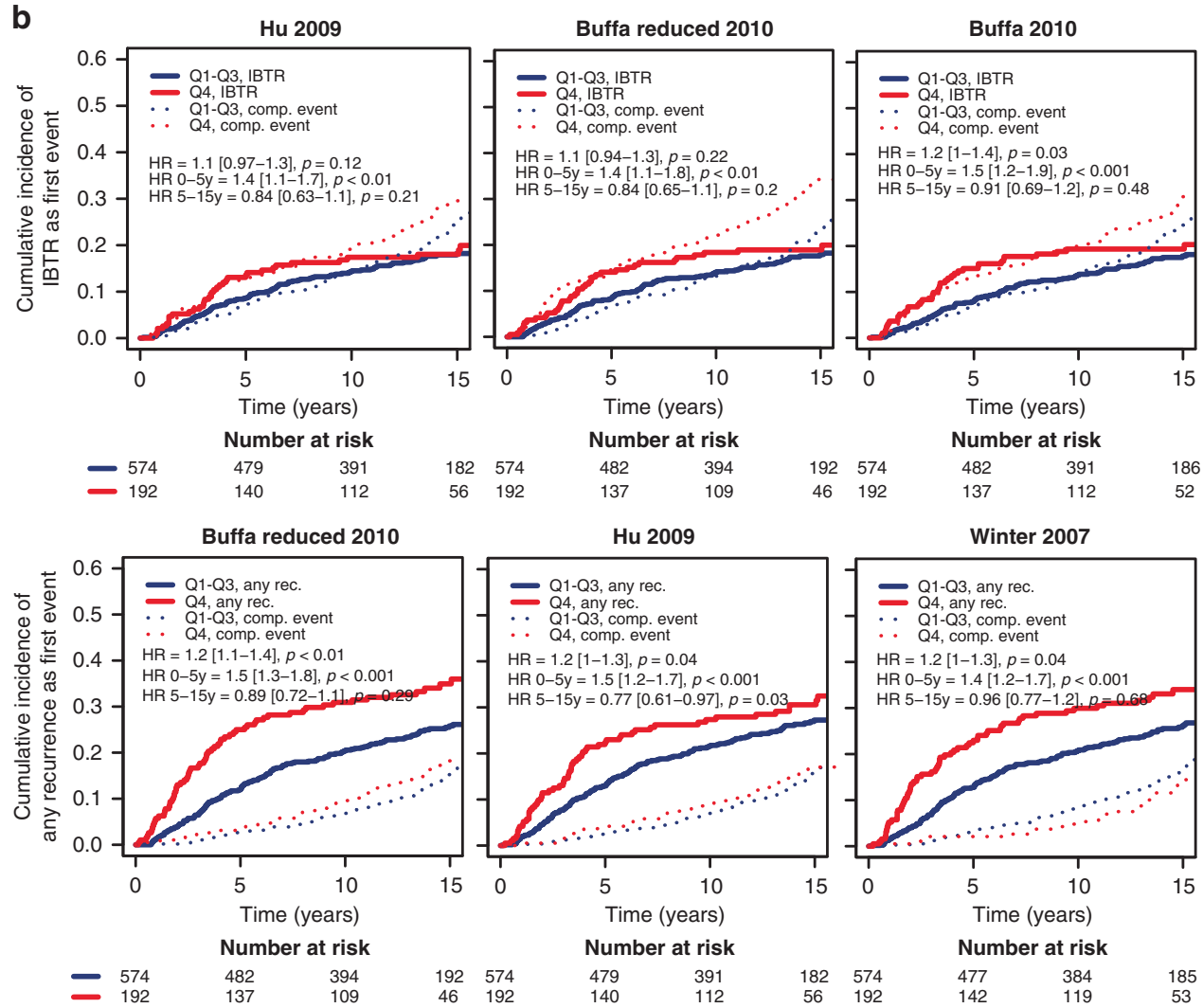

Number at risk
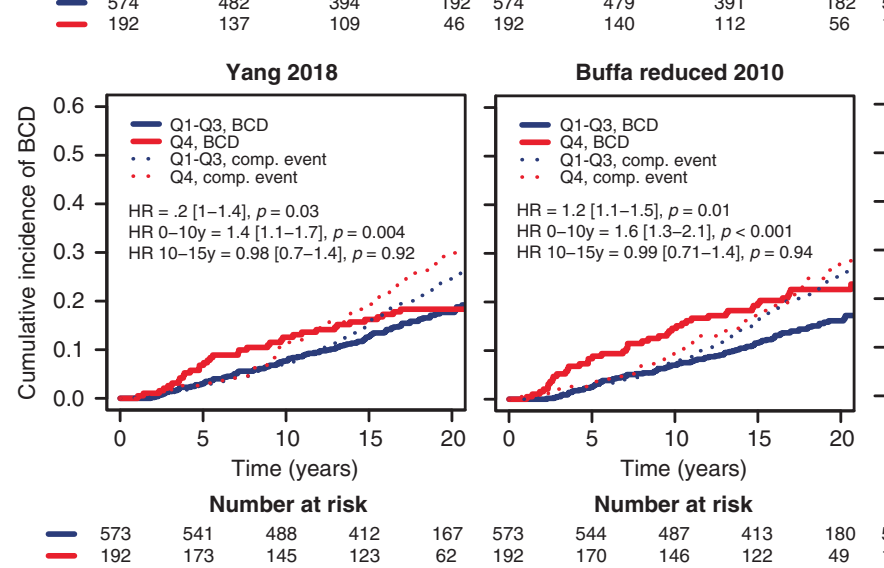

$\begin{array}{rr}82 & 574 \\ 6 & 192\end{array}$

Number at risk

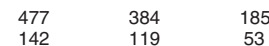

Hu 2009

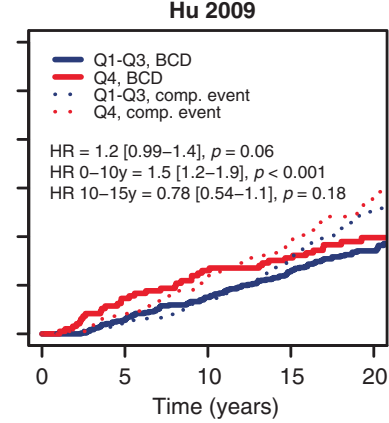

Time (years)
Number at risk

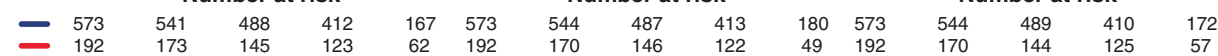

Fig. 6 Hypoxic gene-expression signatures in relation to recurrence and BCD. Forest plot presenting HR of hypoxic signature scores as continuous variables in relation to IBTR during the first 5 years after the primary tumour (a). For all rows, $n$ and events were 766 and 75 , respectively. Competing risk curves presenting the relationship between risk of IBTR, any recurrence, or BCD as first event. For each endpoint, the three hypoxia signatures with the strongest association to outcome are shown (b). The scores were plotted as a dichotomous variable of high vs. low, where low included quartile 1-3 (Q1-3, blue line), and high included quartile 4 (Q4, red line). Survival data presented as text in the plot area were obtained from Cox proportional hazards model with the score as a continuous variable. 


\section{DATA AVAILABILITY}

The gene-expression datasets analysed during this study are available at Gene Expression Omnibus with accession number GSE119295. The IHC datasets generated and analysed during the current study are available from the corresponding author on reasonable request.

\section{REFERENCES}

1. Harvey JM, Clark GM, Osborne CK, Allred DC. Estrogen receptor status by immunohistochemistry is superior to the ligand-binding assay for predicting response to adjuvant endocrine therapy in breast cancer. J Clin Oncol. 1999; 17:1474-81.

2. Clarke M, Collins R, Darby S, Davies C, Elphinstone P, Evans V, et al. Effects of radiotherapy and of differences in the extent of surgery for early breast cancer on local recurrence and 15-year survival: an overview of the randomised trials. Lancet. 2005:366:2087-106.

3. Early Breast Cancer Trialists' Collaborative Group, Darby S, McGale P, Correa C, Taylor C, Arriagada R, et al. Effect of radiotherapy after breast-conserving surgery on 10-year recurrence and 15-year breast cancer death: meta-analysis of individual patient data for 10,801 women in 17 randomised trials. Lancet. 2011;378: 1707-16.

4. Lundstedt $D$, Gustafsson $M$, Malmström $P$, Johansson KA, Alsadius $D$, Sundberg $A$, et al. Symptoms 10-17 years after breast cancer radiotherapy data from the randomised SWEBCG91-RT trial. Radiother Oncol. 2010;97:281-7.

5. Lundstedt D, Gustafsson M, Steineck G, Malmström P, Alsadius D, Sundberg A, et al. Risk factors of developing long-lasting breast pain after breast cancer radiotherapy. Int J Radiat Oncol Biol Phys. 2012;83:71-8.

6. Taylor C, Correa C, Duane FK, Aznar MC, Anderson SJ, Bergh J, et al. Estimating the risks of breast cancer radiotherapy: evidence from modern radiation doses to the lungs and heart and from previous randomized trials. J Clin Oncol. 2017;35: 1641-9.

7. Cohen-Jonathan-Moyal E, Vendrely V, Motte L, Balosso J, Thariat J. Radioresistant tumours: From identification to targeting. Cancer Radiother. 2020;24:699-705.

8. Gray LH, Conger AD, Ebert M, Hornsey S, Scott OC. The concentration of oxygen dissolved in tissues at the time of irradiation as a factor in radiotherapy. $\mathrm{Br} J$ Radiol. 1953;26:638-48.

9. Vaupel P. Prognostic potential of the pre-therapeutic tumor oxygenation status. Adv Exp Med Biol. 2009;645:241-6.

10. Wang GL, Jiang BH, Rue EA, Semenza GL. Hypoxia-inducible factor 1 is a basichelix-loop-helix-PAS heterodimer regulated by cellular $\mathrm{O} 2$ tension. Proc Natl Acad Sci USA. 1995;92:5510-4.

11. Tian H, Hammer RE, Matsumoto AM, Russell DW, McKnight SL. The hypoxiaresponsive transcription factor EPAS1 is essential for catecholamine homeostasis and protection against heart failure during embryonic development. Genes Dev. 1998;12:3320-4.

12. Jaakkola P, Mole DR, Tian YM, Wilson MI, Gielbert J, Gaskell SJ, et al. Targeting of HIF-a to the von Hippel-Lindau ubiquitylation complex by o2-regulated prolyl hydroxylation. Science. 2001;292:468-72.

13. Jiang BH, Rue E, Wang GL, Roe R, Semenza GL. Dimerization, DNA binding, and transactivation properties of hypoxia-inducible factor 1. J Biol Chem. 1996;271: 17771-8.

14. Vaupel $P$, Mayer A. Hypoxia in cancer: significance and impact on clinical outcome. Cancer Metastasis Rev. 2007;26:225-39.

15. Jögi A Tumour hypoxia and the hypoxia-inducible transcription factors: key players in cancer progression and metastasis. In: Mazurek S, Shoshan MC, editors. Tumor cell metabolism. Wien: Springer-Verlag; 2014.

16. Bos R, van der Groep P, Greijer AE, Shvarts A, Meijer S, Pinedo HM, et al. Levels of hypoxia-inducible factor-1alpha independently predict prognosis in patients with lymph node negative breast carcinoma. Cancer. 2003;97:1573-81.

17. Jögi A, Ehinger A, Hartman L, Alkner S. Expression of HIF-1alpha is related to a poor prognosis and tamoxifen resistance in contralateral breast cancer. PLoS ONE. 2019;14:e0226150.

18. Generali D, Berruti A, Brizzi MP, Campo L, Bonardi S, Wigfield S, et al. Hypoxiainducible factor-1alpha expression predicts a poor response to primary chemoendocrine therapy and disease-free survival in primary human breast cancer. Clin Cancer Res. 2006;12:4562-8.

19. Loncaster JA, Harris AL, Davidson SE, Logue JP, Hunter RD, Wycoff CC, et al. Carbonic anhydrase (CA IX) expression, a potential new intrinsic marker of hypoxia: correlations with tumor oxygen measurements and prognosis in locally advanced carcinoma of the cervix. Cancer Res. 2001;61:6394-9.

20. Harris BH, Barberis A, West CM, Buffa FM. Gene expression signatures as biomarkers of tumour hypoxia. Clin Oncol. 2015;27:547-60.

21. Ye IC, Fertig EJ, DiGiacomo JW, Considine M, Godet I, Gilkes DM. Molecular portrait of hypoxia in breast cancer: a prognostic signature and novel HIFregulated genes. Mol Cancer Res. 2018;16:1889-901.
22. Malmström $P$, Holmberg L, Anderson $H$, Mattsson J, Jonsson PE, TennvallNittby $L$, et al. Breast conservation surgery, with and without radiotherapy, in women with lymph node-negative breast cancer: a randomised clinical trial in a population with access to public mammography screening. Eur J Cancer 2003;39:1690-7.

23. Killander F, Karlsson $P$, Anderson $H$, Mattsson J, Holmberg $E$, Lundstedt $D$, et al. No breast cancer subgroup can be spared postoperative radiotherapy after breast-conserving surgery. Fifteen-year results from the Swedish Breast Cancer Group randomised trial, SweBCG 91 RT. Eur J Cancer. 2016;67:57-65.

24. Sjöström M, Lundstedt D, Hartman L, Holmberg E, Killander F, Kovacs A, et al. Response to radiotherapy after breast-conserving surgery in different breast cancer subtypes in the Swedish Breast Cancer Group 91 Radiotherapy Randomized Clinical Trial. J Clin Oncol. 2017;35:3222-9.

25. Leung SCY, Nielsen TO, Zabaglo L, Arun I, Badve SS, Bane AL, et al. Analytical validation of a standardized scoring protocol for Ki67: phase 3 of an international multicenter collaboration. NPJ Breast Cancer. 2016;2:16014.

26. Elston CW, Ellis IO. Pathological prognostic factors in breast cancer. I. The value of histological grade in breast cancer: experience from a large study with long-term follow-up. Histopathology. 1991;19:403-10.

27. Goldhirsch A, Winer EP, Coates AS, Gelber RD, Piccart-Gebhart M, Thurlimann B, et al. Personalizing the treatment of women with early breast cancer: highlights of the St Gallen International Expert Consensus on the Primary Therapy of Early Breast Cancer 2013. Ann Oncol. 2013;24:2206-23.

28. Sjöström M, Chang SL, Fishbane N, Davicioni E, Hartman L, Holmberg E, et al Comprehensive transcriptomic profiling identifies breast cancer patients who may be spared adjuvant systemic therapy. Clin Cancer Res. 2020;26:171-82.

29. Piccolo SR, Sun Y, Campbell JD, Lenburg ME, Bild AH, Johnson WE. A singlesample microarray normalization method to facilitate personalized-medicine workflows. Genomics. 2012;100:337-44.

30. Buffa FM, Harris AL, West CM, Miller CJ. Large meta-analysis of multiple cancers reveals a common, compact and highly prognostic hypoxia metagene. $\mathrm{Br} J$ Cancer. 2010;102:428-35.

31. Koong AC, Denko NC, Hudson KM, Schindler C, Swiersz L, Koch C, et al. Candidate genes for the hypoxic tumor phenotype. Cancer Res. 2000;60:883-7.

32. Elvidge GP, Glenny L, Appelhoff RJ, Ratcliffe PJ, Ragoussis J, Gleadle JM. Concordant regulation of gene expression by hypoxia and 2-oxoglutarate-dependent dioxygenase inhibition: the role of HIF-1alpha, HIF-2alpha, and other pathways. J Biol Chem. 2006;281:15215-26.

33. Hu Z, Fan C, Livasy C, He X, Oh DS, Ewend MG, et al. A compact VEGF signature associated with distant metastases and poor outcomes. BMC Med. 2009;7:9.

34. Mense SM, Sengupta A, Zhou M, Lan C, Bentsman G, Volsky DJ, et al. Gene expression profiling reveals the profound upregulation of hypoxia-responsive genes in primary human astrocytes. Physiol Genomics. 2006;25:435-49.

35. Sorensen BS, Toustrup K, Horsman MR, Overgaard J, Alsner J. Identifying pH independent hypoxia induced genes in human squamous cell carcinomas in vitro. Acta Oncol. 2010:49:895-905.

36. Winter SC, Buffa FM, Silva P, Miller C, Valentine HR, Turley $H$, et al. Relation of a hypoxia metagene derived from head and neck cancer to prognosis of multiple cancers. Cancer Res. 2007;67:3441-9.

37. Farmer $P$, Bonnefoi $H$, Becette $V$, Tubiana-Hulin $M$, Fumoleau $P$, Larsimont $D$, et al. Identification of molecular apocrine breast tumours by microarray analysis. Oncogene. 2005;24:4660-71.

38. Yang L, Roberts D, Takhar M, Erho N, Bibby BAS, Thiruthaneeswaran N, et al Development and validation of a 28-gene hypoxia-related prognostic signature for localized prostate cancer. EBioMedicine. 2018;31:182-9.

39. Foroutan M, Bhuva DD, Lyu R, Horan K, Cursons J, Davis MJ. Single sample scoring of molecular phenotypes. BMC Bioinformatics. 2018;19:404.

40. Waldron L, Riester M. HGNChelper: identify and correct invalid HGNC human gene symbols and MGI mouse gene symbols. R package version 0.8.1. 2019. https://CRAN.R-project.org/package=HGNChelper.

41. Stelzer G, Rosen R, Zimmerman S, Twik M, Fishilevich S, Iny Stein T, et al. The GeneCards Suite: From Gene Data Mining to Disease Genome Sequence Analysis. Current Protocols in Bioinformatics 2016;54:1.30.1-33.

42. Gray B. cmprsk: Subdistribution analysis of competing risks. R package version 2 . 2-7.

43. Schoenfeld D. Partial residuals for the proportional hazard regression model. Biometrika 1982;69:239-41.

44. Nordsmark M, Bentzen SM, Rudat V, Brizel D, Lartigau E, Stadler P, et al. Prognostic value of tumor oxygenation in 397 head and neck tumors after primary radiation therapy. An international multi-center study. Radiother Oncol. 2005;77: $18-24$.

45. Overgaard J, Eriksen JG, Nordsmark M, Alsner J, Horsman MR, Danish H, et al Plasma osteopontin, hypoxia, and response to the hypoxia sensitiser nimorazole in radiotherapy of head and neck cancer: results from the DAHANCA 5 randomised double-blind placebo-controlled trial. Lancet Oncol. 2005;6:757-64. 
1156

46. Brizel DM, Scully SP, Harrelson JM, Layfield LJ, Bean JM, Prosnitz LR, et al. Tumor oxygenation predicts for the likelihood of distant metastases in human soft tissue sarcoma. Cancer Res. 1996;56:941-3.

47. Harris AL. Hypoxia-a key regulatory factor in tumour growth. Nat Rev Cancer. 2002;2:38-47.

48. Rankin EB, Giaccia AJ. Hypoxic control of metastasis. Science. 2016;352:175-80.

49. Helczynska K, Kronblad A, Jögi A, Nilsson E, Beckman S, Landberg G, et al. Hypoxia promotes a dedifferentiated phenotype in ductal breast carcinoma in situ. Cancer Res. 2003;63:1441-4.

\section{ACKNOWLEDGEMENTS}

We wish to acknowledge the skilful technical assistance of Kristina Lövgren, and Sara Baker and Carina Forsare for database management and support. We gratefully acknowledge the South Swedish and West Swedish Breast Cancer Groups and all participating departments of Surgery, Pathology and Oncology. We thankfully acknowledge S. Laura Chang (Exact Sciences), Felix Feng (University of California, San Francisco), Corey Speers (University of Michigan) and Lori Pierce (University of Michigan) for mRNA retrieval and generation of gene-expression data.

\section{AUTHOR CONTRIBUTIONS}

Conception and design: AJ, EH, JT, MF, MS, PK and PM. Data acquisition, analysis and interpretation: AJ, EH, EN, FK, LMFL-L, JT, MF, MS, PK and PM. Writing, review and/or revision of the manuscript: AJ, EH, EN, FK, LMFL-L, JT, MF, MS, PK and PM. Administrative, technical or material support: AJ, EH, LMFL-L, JT, MF, MS, PK and PM. Study supervision: AJ, EH, EN, FK, LMFL-L, JT, MF, MS, PK and PM.

\section{FUNDING}

This work was supported by Allmänna Sjukhusets i Malmö stiftelse för bekämpande av cancer (cancerforskningmalmo.se, AJ), The Anna and Edwin Berger Foundation (MF and EN), Governmental Funding of Research within the National Health Services (ALF) (MF and EN), the Gunnar Nilsson Cancer Society (MF and EN), the Hans von Kantzows Foundation (AJ), Marianne and Marcus Wallenberg Foundation (EN), the Mrs Berta Kamprad Research Foundation (MF, PM), the O.E. and Edla Johansson's foundation (oervetstiftelse.se, AJ), the Percy Falk Foundation (c/o Thomas Kramar, Sweden, AJ), the Swedish Breast Cancer Association (BRO)(FK, MF, PM, and EN), the Swedish Cancer and Allergy Foundation (MF), the Swedish Cancer Society (MF, PM, and EN), and the Swedish Cancer Foundation (190479 Pi; LMFL-L). The funders had no role in study design, data collection, decision to publish, or preparation of the manuscript.

\section{ETHICS APPROVAL AND CONSENT TO PARTICIPATE}

The trial and follow-up including tissue microarrays (TMAs) were conducted in accordance with the declaration of Helsinki and approved by the local ethics committees. Gene-expression analyses were approved by the Lund University Ethical Review Board (2010/127, 2015/548). Oral informed consent was obtained from all patients, which was approved by the Ethical Review Board for the original trial and for the gene-expression study.

\section{CONSENT FOR PUBLICATION}

No individual person's data is presented.

\section{COMPETING INTERESTS}

The authors AJ, FK, EN, JT, LMFL-L and MS declare no competing interests. PK, EH, PM and MF research contract with PFS Genomics.

\section{ADDITIONAL INFORMATION}

Supplementary information The online version contains supplementary material available at https://doi.org/10.1038/s41416-021-01630-4

Correspondence and requests for materials should be addressed to Annika Jögi.

Reprints and permission information is available at http://www.nature.com/ reprints

Publisher's note Springer Nature remains neutral with regard to jurisdictional claims in published maps and institutional affiliations.

\begin{abstract}
(c) (1) Attribution 4.0 Internationa adaptation, distribution and reproduction in any medium or format, as long as you give appropriate credit to the original author(s) and the source, provide a link to the Creative Commons license, and indicate if changes were made. The images or other third party material in this article are included in the article's Creative Commons license, unless indicated otherwise in a credit line to the material. If material is not included in the article's Creative Commons license and your intended use is not permitted by statutory regulation or exceeds the permitted use, you will need to obtain permission directly from the copyright holder. To view a copy of this license, visit http://creativecommons. org/licenses/by/4.0/.
\end{abstract}

(c) The Author(s) 2021 